\title{
Semantički potencijal emocija kroz jezike i kulture
}

\section{Sažetak}

U radu se analiziraju emocije i njihov semantički i lingvokognitivni potencijal, koji u kolokativnom smislu kroz različite jezike i kulture prenose potpuno različit emotivni doživljaj. Teorijska postavka rada je razrada psiholingvističke teorije znanja, odnosno psiholingvistički aspekt jezičkih oznaka za emocije i izrazi koji prenose značenje o emotivnom iskustvu. U nauci je prevaziđeno mišljenje da čovek poseduje šest emocija, a najnovije studije su pokazale da ih je samo četiri: sreća, tuga, strah i bes. Rad se fokusira na semantičkoj analizi navedenih emocija i njihovoj jezičkoj realizaciji u ljudskoj komunikaciji. Kulturološki elementi su sastavni deo psiholoških faktora, mereni dimenzijama valence, odnosno vrednosnim skalama od prijatne do neprijatne, kao i salijentnošću, odnosno istaknutosti nadražaja, od niskog do visokog. Emocija i kultura su se po ko zna koji put semantički sjedinili, krenuvši od čovekovog telesnog do emotivnog iskustva na poligonu različitih identiteta i kultura.

Ključne reči: psiholingvistika, emocija, kultura, valenca, salijentnost, jezička realizacija

\section{Uvod}

Cilj ovog istraživanja jeste da pomeri granice razmatranja o semantici emocija i njihovoj jezičkoj realizaciji putem psihofizičkih stanja i reakcija ljudi u različitim kulturama.Teorijska postavka rada je lingvokognitivnog tipa, jer prikazuje jezičku realizaciju emocija kroz prostor i vreme.

Sagledana je uloga kulturoloških aspekata u semantičkoj kategorizaciji emocija kroz razne jezike i kulture, poentirajući da su kulturološki elementi neodvojivi od jezika i psiholoških faktora. Opšti elementi kulture srastaju sa jezikom u domenu emocija. 
U većini jezika postoji jezički znak za emocije, kao i manji glosar izraza kojima se objašnjava emotivno iskustvo. Analiza jezičkih potencijala, leksema za emocije, daje uvid u stanje kako se u jednoj društveno-jezičkoj sredini procenjuju emocije, gde kultura bira koji će se psihološki i društveni aspekti emotivne situacije percipirati i jezički realizovati.

U svetu je postojalo uvreženo mišljenje da čovek ima šest primarnih emocija, tipa sreća, iznenađenje, strah, gađenje, bes i tuga. Međutim najnovije studije su pokazale (Univerzitet Glaszgov) da postoje četiri osnovne čovekove emocije sreća, tuga, strah i bes.

Pristupilo se višeaspektnoj psiholiongvističkoj analizi značenja i smisla emocija preko skala valence i salijentnosti, što je za rezultat dalo kvalitativno nove jezičke realizacije. Analizirane su lekseme iz semantičkih polja sreće, tuge, straha i besa pošto se ove četiri emocije u psihologiji smatraju primarnim, a ostale su ilustrovane shodno Kejganovoj analizi.

Primenjivao se induktivno-deduktivni, komparativni (radi upoređenja razlika i sličnosti emocija u raznim jezicima) i deskriptivno-analitički metod (istraživanje i opis različitih značenja leksema za emocije), a korpusna građa je utemeljena na primerima pisanog jezika iz štampanih i elektronskih verzija knjiga i radova iz oblasti kognitivnih nauka.

\section{Valenca, salijentnost i prepoznavanje emocija}

U radu su emocije određene psihološki, jezički i kulturološki, jer jezik ne predstavlja puki znak, već skup izraza u jeziku o emotivnom iskustvu, dajući uvid u emocije koje postoje u određenoj kulturi.

Emotivni život i prepoznavanje emocija samo se naizgled čini identično kod svih ljudi, tipa iznenađenje i strah imaju isti pokret obrva. Ali nije tako. Ljudi na različite načine doživljavaju svoje emocije koje ispoljavaju, a sa kojima se psihološki posmatrano kroz život bore, pokušavajući da se izbore na kreativan način, kako bi vodili bogatiji život. Moderne humanističke nauke akcenat stavljaju na ličnost i snagu ljudskih sposobnosti koje se odnose na percepciju tekstova, vizuleni identitet i govor.

Emocije se klasifikuju kao pozitivne ili destruktivne, a na njihovo ispoljavanje utiču pojedinačna društva i kulture, kao i pojedinačna ponašanja, oseti, saznanja, mentalno i javno zdravlje određene zajednice. Kultura 
istoka i zapada emocije posmatra različito, od inspirativnih do provaktivnih, destrutkivnih do kreativnih, praznih do ispunjenih.

Predmet i analiza rada je zasnovana na psihološkim osnovama Kejganove psihološke teorije o emocijama, koja se temelji na shvatanju jezika kao lingvokognitivnoj i kulturološkoj pojavi, jer su kulturološki elementi nerazdvojni od psiholoških faktora.

Shodno Kejganu, kada ljudi procenjuju sličnosti između dve reči za emociju, bez dodatnih informacija, na osnovu slika, zvukova, osećanja ili prirode okruženja, teže ka tome da se oslone na dve dimenzije: valence (vrednosti) od prijatne do neprijatne i salijentnosti (istaknutost nadražaja) od niske do visoke, što ukazuje na naročito zanimanje za intiman tonalitet osećanja jedinke. (Kejgan 2015:186). Emocije kao jezičke jedinice se preko psiholoških i fizioloških parametara integrišu u signale, koji nose semantičko značenje.

Visoka salijentnost

\begin{tabular}{|l|c|c|c|}
\hline Neprijatna valenca & $\begin{array}{c}\text { Ljutnja } \\
\text { Strah } \\
\text { Gađenje }\end{array}$ & $\begin{array}{c}\text { Ljubav } \\
\text { Uzbuđenje } \\
\text { Radost }\end{array}$ & Prijatna valenca \\
\hline & $\begin{array}{c}\text { Tuga } \\
\text { Dosada } \\
\text { Usamljenost }\end{array}$ & $\begin{array}{c}\text { Spokojstvo } \\
\text { Estetsko osećanje } \\
\text { Opuštenost }\end{array}$ & \\
\hline
\end{tabular}

Niska salijentnost

Emocije su određene kulturološki. Povezane su sa jezikom, kao skup izraza o nekom emotivnom iskustvu. Emitovani i receptivni signal ili poruka, odnosno reč, rađa se iz društveno-kulturološkog miljea, na bazi čega se stvara čovekova individualna psihologija i prodor u ljudsku svest. ${ }^{1}$ Interakcija psihologije i lingvistike proizvela je psiholingvistiku, čiji je ključ analize jezik izveden iz čovekovih spoznajnih procesa.

$\mathrm{U}$ prethodno navedenim kvadratima su raspoređene reči (semantički pojmovi kao proizvod čovekove psihe, gde se značenje, smisao i kon-

$1 \quad$ O jeziku i misli je prvo govorio Vilhem von Humbolt, koji se smatra rodonačelnikom psiholingvistike. 
tekst realizuju iz unutrašnjeg čovekovog sveta) koje označavaju emociju na osnovu dve dimenzije valence i salijentnosti.

Pažnja je usmerena na termine, odnosno izraze za emociju raspoređene $u$ jednom od četiri kvadrata koja su napravljena tako što su se ukrstile dimenzije valence i salijentnosti. Radost ima prijatnu valencu i visoku salijentnost. Dosada ima neprijatnu valencu i nisku salijentnost, strah ima neprijatnu valencu i visoku salijentnost.

Čovek stalno oseća, ali retko misli, predočio je Jerotić na jednom od svojih predavanja. Stoga se misao i svest ${ }^{2}$ terminološki prepliću kod lingvista koji nemaju psihološku potku.

\section{Terminološko određenje emocija}

Emocija je po definiciji psihologa, uzbuđeno stanje organizma izazvano subjektivno značajnim, važnim stimulusom, odnosno situacijom, koje viscelarno, motorno, motivaciono i mentalno priprema subjekta za adaptivnu aktivnost. Emocije se javljaju na tri plana: 1) fiziološkom (ubrzan puls, širenje zenica, ubrzano disanje, pojačano lučenje adrenalina, povečanje nivoa šećera u krvi; 2) subjektivnom (doživljaj specifičnog kvaliteta osećanja, tipa sreća, tuga); 3) bihejvioralnom (spolja vidljive manisfestacije emocija, tipične promene u ponašanju, stavu tela, gestovima, mimici). Te je emocija složena kognitivno-fiziološko-bihejvioralna reakcija sa dvojakom funkcijom: adaptacijom i komunikacijom.

Po definiciji Oksfordskog rečnika emocija je svaka uzbuđenost ili uznemirenost uma, osećanja, strasti: svako žestoko ili uzbuđeno mentalno stanje. Goleman je koristi kada izražava osećanja i misli, psihološka i biološka stanja i delovanja. A za primarne je izdvojio ljutnju, tugu, strah, radost, ljubav, začuđenost, gađenje, stid.

U radu će se dalje izložiti psihološko jezičko određenje pojava koje su značajne za semantičku analizu. Prema Ufimcevoj asocijativno polje stimulusa je ne samo fragment verbalne memorije čoveka, već i fragment slike sveta etnosa, koja se odslikava u svesti prosečnog nosioca kulture, njegovih motiva i ocena, i, kao posledica toga, njegovih kulturnih stereotipa. Prema broju reakcija strukturu svakog asocijativnog polja čine cen-

2 Jezička svest dovodi do terminoloških zabuna 
tar, bliža, dalja i krajnja periferija i lako je uočiti granicu među njima. Kultura u kojoj ispitanici žive značajnije utiče na jezičku svest od jezika kojim se oni služe, pa pripadnici iste jezičke zajednice koji žive u različitim kulturama imaju različite asocijacije. ${ }^{3}$

Autoriteti iz psiholingvistike ukazuju da se na engleskom, kineskom, japanskom, indonežanskom i danskom jeziku izrazi za emociju uklapaju u navedenu šemu, iako se Azijci razlikuju od Amerikanaca, jer su skloniji umerenijem izražavanju uzbuđenja i obuzdavanju emocija. Problem jednostavne četvoroćelijske semantičke strukture ogleda se u tome što ju je teško koristiti kad ispred sebe imamo mešavinu osećanja. Mnogi studenti sa približavajem kraja semestra osećaju mešavinu osećanja i radosti i tuge, jer napuštaju kampuse i zbog te mešavine osećanja njihovo stanje nije lako rasporediti ni u jedan od četiri kvadrata.

Dimenzije valence i salijentnosti za reči kojima se označavaju emocije nisu verni biološkim standardima, kao ni opaženim osećajnim stanjima koja pobuđuju emocije. Čak i odrasli koji ne mogu da dožive nikakvu autonomnu povratnu reakciju iz tela do mozga, kao i pacijenti sa lezijama amigdale, oslanjaju se na valencu i salijentnost u izboru reči za klasifikovanje emocionalnih događaja. Odrasli se koriste karakteristikama pola ili uzrasta, a ne valence i salijentnosti, da procene sličnosti između fotografija ljudskih lica.

Reči gađenje i ljutnja imaju istu valencu i salijentnost, ali ni profil mozga ni bihevijoralna opažanja ne ukazuju na sličnost tih emocija. Obe reči pripadaju porodici povezanih semantičkih mreža.

Na primer, jedna mreža kojoj pripada izraz ljutnja sadrži semantičku predstavu osujećenosti, uvrede, napada, ili prinude. Druga mreža sadrži predstavu o sopstvenim greškama. Treća sadrži predstavljanje događaja koji narušavaju čovekov osećaj za pravdu. Mreže su praćene različitim osećanjima, šemama i stanjima mozga, iako su objedinjene izrazom ljutnja. Snaga veza među izrazima zavisi od konteksta. Izvesno je, ali nije dokazano, da upotreba semantičkog izraza odražava emociju, ako ujedno aktivira i šemu opažaja. Izraz prestravljen povezaće se više sa šemom nego reč nesiguran. Ljudi koji su iskusili strah, vojnici u ratu, pre će aktivirati šemu nego čovek koji nikad nije bio u vojsci.

3 Уфимцева, Н.В. (2011). Языковое сознание: динамика и вариативность. Москва: Российская академия наук. Институт языкознания. 
Semantički pojmovi dobro i loše privlače različite ideje $i$ iskustva koja se odlikuju istom semantičkom evaulacijom na zasebnim putanjama. Tako su travari u 16. veku svrstali pšenicu koja spada u travu u istu kategoriju sa heljdom koja nije trava. Zato što u nazivu obe reči imaju reč pšenica (engleski wheat, buchwheat). Odgovor tužno koji se dobije na pitanje kako se osećaš kad se sazna da je nekome umro blizak rođak ne može da prenese jačinu iskustva ožalošćenog. Kako se rečima za emocije u engleskom jeziku imenuju grupe različitih osećanja, a ne mogu da se odrede specifični oblici tih stanja u različitim kontkstima, njima se ne mogu imenovati prirodne pojave, kao što se mogu imenovati izrazima pun mesec, olujni oblak, palmino drvo i trudna žena

Psiholingvistička teorija znanja obuhvata analizu jezičke svesti, ličnosti i slike sveta. Jezička svest, jezik i mišljenje u komunikaciji su parametri o kojima je detaljno razmatrao Čomski.

Problemi kod opisivanja reči za izražavanje emocije je u tome što svaka reč ima više značenja i dvosmislena je.

Tako na primer Amerikanci koriste izraz strah da označe zabrinutost zbog povrede, gubitka imovine, društvenog odbacivanja, neuspeha u poslu, nepoznatih okolnosti i usamljenosti. Sve te okolnosti praćene su subjektivnim osećanjem, a svaka okolnost ima biološke osnove.

Studenti iz sedam kultura bili su saglasni u pogledu porekla i rasprostranjenosti realnih strahova (strah od opasnih životinja, teških bolesti).

Uočene su kulturološke i polne razlike manje realnih strahova (strah od bubašvabe, od mnoštva ljudi ili udara groma).

Nasledni faktor kod manje realnih strahova je mnogo veći od naslednosti realnih strahova, zbog različitih bioloških osnova. (Kejgan 2015: 194).

Dvosmislenost većine reči za obeležavanje emocija leži u činjenici da se opisuju osećanja koja su veoma ili blisko slična. Semantički posmatrano, radi se o različitim asocijativnom poljima, gde se značenjski bliske reči grupišu u posebna asocijativna semantička polja. Shodno navedenom, američki socijalni fobičari koriste reč, odnosno leksemu strepnja, (kada ne može da se izađe na kraj sa životnim problemima) za anksiozan, zabrinut ili prestrašen kad žele da opišu komunikaciju sa neznancima.

Japanski socijalni fobičari biraju izraze koji su u engleskoj verziji bliži značenju nelagode i stida. Poreklo osećanja, njegova neprijatna i salijentna priroda i posledice društveno nepodesnog ponašanja slični su. 
Amerikanci i Japanci koriste semantičke izraze koji imaju različito značenje, jer su Japanci brižniji od Amerikanaca kada je reč o očuvanju sklada u društvenim odnosima. Japanci poštuju dva kategorička imperativa: da nikoga ne uvrede i da budu obzirni prema sagovornikovoj društvenoj ulozi i položaju. Shodno tome, Japanci imaju četiri glagola za izraz jesti, koji određuju društveni položaj osobe koja jede i odnos između onog ko govori i onog ko sluša. Engleski je neosetljiv prema tim razlikama.

Ljudi drugačije pokazuju strah, ljutnju ili tugu, ali se sva lica koja pripadaju toj semantičkoj kategoriji slično nazivaju. Slično je i sa bojama. Svako će proceniti vidljive boje spektra kao što su crvena, zelena, žuta i plava, pre nego što će ih odrediti kao kontinuum talasne dužine. Ljudi većinom odaberu istu reč za sve nijanse koje su u opsegu talasnih dužina određene boje. Statičnost je svojstvo jezika, a dinamičnost je svojstvo emocija. Reči za emocije, kao fotografija plesačice, pretvaraju dinamičan događaj u događaj koji je zamrznut u vremenu i prostoru. U trenutku kad je neka žena izjavila kako je srećna pošto je pročitala obaveštenje o svom unapređenju, njeno emocionalno stanje je već počelo da se menja.

Umesto zaključka, konstatovalo bi se sledeće: Psiholingvistički pristup u sagledavanju funkcionisanja jezika nije limitiran na analizu samih jezičkih pojava. Ovde su uključeni i psihički život čovekove ličnosti, koji se nalazi u posebnoj društveno-kulturološkoj zajednici, pri čemu se formira njegova individualna slika sveta i njegovog realnog ili nerealnog okruženja.

\section{Uticaj kulture i kulturnog obrasca na odabir izraza za emocije}

Izrazi za emocije i rečenice u kojima se oni javljaju, usled različitih životnih iskustava i ideologije, kod različitih kultura su ugrađeni u posebne semantičke mreže. Semantički središni pojam je prototip koji je povezan sa aktuelnim događajima na granici mreže srodnih predstava. Po Kejganu, Vrabac je prototip pojma ptica za stanovnike severne Amerike, a ne za Indonežane. Prototip za emocionalni izraz može da se odnosi na karakternu crtu ili na osećanja, uzroke ili posledice emocije. Njegova analiza više od stotinu kineskih reči povezanih sa pojmom stida pokazala je da u tom jeziku postoje izrazi za stidljiv karakter, sklonost crvenjenju, za postupke kojima se krše društvene norme, ljutnju prema onima koji su odgovorni za nastajanje te emocije i za bestidne osobe. 
Izraz apatija prototip je za engleski izraz potištenost, dok je za Indijce prototip tog izraza reč beznađe, za one iz Sri Lanke prototip je razočaranje, a za Indonežane tuga. Današnji studenti iz severne Amerike smatraju da je majčinska, a ne Božija ljubav prototip za pojam ljubav. Srednjovekovni monasi i monahinje bi obrnuli taj profil. Za Seneku, rimskog filozofa i pisca, koji je stvarao na početku modernog doba, prototip latinskog pojma apatija bilo je poželjno stanje spokojnog mira, dok je za savremene pisce apatija prototip nepoželjnog stanja potištenosti. Nemački izraz Angst predstavlja neprijatnu emociju koja prati nemogućnost da proniknemo u budućnost. Kako su svi budući događaji nesagledivi, jedino bi se u kulturi u kojoj se to psihološko stanje smatra neuobičajeno uznemirujućim, mogao iskovati pojam koji taj oblik nesigurnosti izdvaja od ostalih.

Sledeće okolnosti izvesno su prototipi nekih uvreženih izraza za emocije koje koriste Amerikanci: smrt prijatelja ili rođaka, ili prekid prijateljstva prototip za tugu; neposredna fizička opasnost prototip je za strah. Očekivanje nekog zadatka ili društvenog neuspeha prototip je za zabrinutost. Doživljena uvreda, prinuda ili izloženost nečijoj nadmoći prototip su za ljutnju. Dobijanje poklona, pohvale ili uspešno obavljen zadatak prototip su za sreću. Iščekivanje novog iskustva prototip je za uzbuđenje. Postupak kojim je neko povređen prototip je za krivicu, a nehotično kršenje društvenih normi prototip je za stid. Jedinke koje emocionalno reaguju na nadražaje koji odstupaju od prototipskog uzroka, označiće se kao devijantne. Anksioznost pred obraćanje prisutnima na velikom društvenom skupu uklapa se u američki prototip, za razliku od anksioznosti prouzrokovane razmišljanjem o preminulom pretku. Prototipi emocionalnih izraza Amerkanaca često se razlikuju od prototipa otkrivenih u drugim kulturama.

Kad američki i japanski učenici prenose svoje emocionalno stanje u trenutku kad se oglasi školsko zvono, japanski učenik će po svoj prilici, pre nego američki, reći da je srećan što je bio s vršnjacima. Američki učenici će biti srećniji kad dobiju neki poklon ili uspešno obave povereni zadatak.

Za uzajamna osećanja između dve jedinke prototip je grčki izraz filija, dok prototip za odgovarajući engleski izraz-naklonost prema prijatelju, ne obuhvata i uzvraćanje te emocije. Za Amerikance, reči srećan i uzbuđen imaju sličnije značenje nego kod Japanaca. Za kineske ispitanike reči stid i strah imaju sličnije značenje nego za Japance. Stid i strah imaju sličnije značenje kod Indonežananego kod Holanđana. 
Na svojstva prototipskih osećanja ili emocija, koja dobijaju istaknuto mesto prilikom opisivanja, utiču i kulturni milje i jedinstven rečnik određene kulture. lako se u mnogim jezicima naglašavaju valenca i salijentnost čovekovog intimnog psihološkog stanja, pripadnici malog broja kultura dodeljuju status prototipa telesnim uzrocima osećanja (vrtoglavici, glavobolji, ubrzanom srčanom ritmu). Nema mnogo jezika u kojima se uzroku ili posledicama emocija daje prednost. Kinezi imaju posebne izraze za stid i krivicu koji ukazuju na uzrok tih emocija, kao i na to da li je subjekt svojim postupcima povredio nekog. Engleski izrazi stid i krivica, kojima se naglašava isključivo mentalno stanje subjekta, ne daju dodatne informacije. Ta kulturološka različitost posledica je dva faktora: uzdizanja individualnog, a ne društvenog konteksta u kojem subjekt deluje i privlačnost premise da mali set osnovnih jedinica, atoma mentalnog života, može da doprinese izuzetnoj raznolikosti emocionalnih fenomena.

Kejgan tvrdi da je rasprostranjenost ili složenost semantičke mreže za emocionalni izraz u funkciji njegovih brojnih semantičkih odlika, kao i određivanja u kojoj meri te odlike izdvajaju jednu reč od ostalih izraza sa sličnim značenjem. Neke njegove kolege psiholozi to nazivaju semantičkom relevantnošću. Takođe on je naveo izraze u slengu koji se odnose na seksualnost, koji su semantički relevantniji za američke muškarce, nego za američke žene. Nežnost ima veću semantičku relevantnost za žene nego za muškarce. Reči strah, zabrinutost, ljutnja i gađenje imaju širu semantičku mrežu od reči spokojstvo, saosećanje i dosada. Stoga će slike ili reči koje ukazuju na prva četiri izraza stvoriti bogatiju semantičku mrežu nego reči iz druge grupe, a kao rezultat toga uslediće veća moždana aktivnost. Pojačana neuronska aktivnost do koje dolazi kad se na ekranu pročitaju reči strah i ljutnja, više zavisi od semantičke mreže, nego od snažnije emocionalne reakcije na te reči.

Ukorenjena društvena shvatanja, izrazi i kulturološke razlike u semantičkim mrežama ukazuju na činjenicu da istraživači ne mogu poći od toga da neka reč ili rečenica ima isto značenje u različitim društvima. Kejgan je navedeno ilustrovao rečenicom Volim te. Amerikanci taj izraz koriste češće nego pripadnici većine društava, ali u njihovom slučaju on je lišen salijentnosti koju ima u drugim kulturama. Bilingvalnim ljudima koji osim izvornog govore i engleski jezik mnogo je lakše da izgovore volim te na engleskom, nego na svom maternjem jeziku, zato što u njihovom ma- 
ternjem jeziku ta fraza ukazuje na dublju emocionalnu vezu. Isti ilustraciju je naveo kad su u pitanju psovke. Psovanje na maternjem jeziku ima upečatljiviji emocionalni prizvuk, koji se gubi kad se isti izraz izgovori na kasnije usvojenom jeziku. Reakcija mozga na različite zvuke često zavisi od značaja koje ti zvuci imaju na slušaoca, a ređe od njihovih objektivnih svojstava.

Te činjenice ukazuju da je nemoguće prevesti sve poznate reči za emociju s jednog jezika na drugi i pretpostaviti kako one i u drugom jeziku imaju isto značenje. Kada je Avgustin, filozof iz 14 veka, razmatrao razlike između svojih osećanja i stanja koja je smatrao bogougodnim, opisao je svoju emociju ovim rečima: Kako sam grešan bio, nečastan i podao, opijen i pokvaren. Većina današnjih Evropljana ili Amerikanaca ne bi mogla da iskusi Avgustinovo stanje, zato što ono iziskuje snažnu veru u Boga, đavola i grešna dela koja dušu osuđuju na čistilište.

\section{Suprotnost između istoka i zapada ${ }^{4}$}

Nerešeno je pitanje zašto su se u starogrčkim i starokineskim društvima razvile različite predstave o ljudima, predmetima i životinjama i njihovim odnosima unutar prirodnog ili društvenog okruženja. Među najvećim drevnim civilizacijama kao što su Kina, Mesopotamija, Egipat i Indija, jedino se u Kini verovalo kako se deca rađaju sa sklonošću ka saosećanju i dobrim delima i jedino se u Kini ispoljavalo relativno odsustvo brige za Boga ili bogove kojima ljudi treba da udovolje i da ih se plaše. Suprotstavljene pretpostavke Grka i Kineza o poreklu prirodnih pojava možda su jedan od temelja različitih lingvističkih opisa ljudi i njihovih emocionalnih mogućnosti.

Kejgan naglašava da evropsko isticanje stabilnih odlika atoma u različitim okruženjima predstavlja osnovu verzije atomske teorije postavljene u 20 veku. Evropljani su pošli od činjenice da je osnovna jedinica jedinka, a ne porodica ili grupa, a svaka jedinka teži ka tome da ostvari nadmoć i reproduktivnu plodnost nadmetanjem, a ne saradnjom s drugima. Kineski izbor energije kao osnove doveo je do stanovišta da prirodne pojave

4 Za istočnu kulturu najlepša leksema je hleb, hleb naš nasušni; za zapadnu, tipa francusku, uvek je to leksema vino. 
odražavaju ravnotežu između sila jin i jang. Dok je jedna sila na vrhuncu, druga opada, obe daju jedinstven doprinos svakom fenomenu.

Po razvojnoj psihologiji, Stari Kinezi i Japanci posmatrali su pojavna svojstva promenljivih prirodnih pojava kao događaje koje treba razumeti. Grci su smatrali da su ti pojavni oblici varljivi, pa su pokušali da zamisle nepromenljive, nevidljive elemente u njihovoj osnovi. Moderni naučnici tragaju za biološkim odlikama straha, zabrinutosti i ljutnje koje se prenose kroz nas. Međutim, ako se zabrinutost zbog susreta s neznancima posmatra kao privremeno odsustvo spokojnog stanja sigurnosti, naučnici bi trebalo da pokušaju da izmere ravnotežu koja vlada između ta dva stanja.

U japanskom jeziku ne postoji jedna jedinstvena reč za vođu, za onog ko uvek prednjači u određenoj grupi. Vođstvo nije lično svojstvo koje jedinka prenosi iz jednog okruženja ili grupe u drugo. Na američkim i evropskim fakultetima na kojima postoje kursevi o vođstvu polazno stanovište je da je za sposobnost predvođenja bilo koje grupe sledbenika neophodan određen set ličnih obeležja, kao što je Napoleonova smelost i samouverenost. Film kao što je Maboroši, s drugim kadrovima u kojima se junaci portretišu kao jedva primetne prilike u dalekoj pozadini krupnog kadra, mogao je da snimi samo japanski režiser.

Kod Kejgana se takođe da primetiti da su suprotstavljeni pogledi na svet pokazali kako pripadnici dve kulture opisuju ljude. Postoje dva komplementarna načina da se opiše neka jedinka. Mogu se navesti nečije karakteristične crte ili opisati nečije ponašanje i sklonosti u različitim okruženjima ili u određenim društvenim ulogama. Prvi set bi trebalo da prevazilazi okruženje, dok drugi pruža informacije o određenom ponašanju koje neko očekuje da vidi. Jedna žena može da bude opisana kao otvorena, neumorna, savesna i prijatna, s jedne, ili kao vredna advokatica, brižna majka dvoje malo dece i član lokalnog udruženja građana i planinarskog kluba, s druge strane. Amerikanci su skloniji prvom opisu, koji ističe crte postojane u različitim okruženjima i trenucima, iako se tim pristupom ne otkriva specifično ponašanje, koje će se, po svoj prilici, ispoljiti u određenim okolnostima. Japanci i Kinezi su skloniji drugom verbalnom stilu.

Pojmovi okvir i obeležje temeljne su vrednosti japanskog društvenog života. Svako lično obeležje, naročito nečija uloga ili položaj u društvu, povezani su s okvirom koji čini društveno okruženje. Neka jedinka je pro- 
fesor određenog predmeta na određenom univerzitetu, a ne samo profesor. U japanskom jeziku ne postoji jedna jedinstvena reč za vođu, onog koji uvek prednjači u određenoj grupi. Vođstvo nije lično svojstvo koje jedinka prenosi iz jednog okruženja ili grupe u drugo.

Tu razliku je upečatljivo ilustrovao u suprotnostima između opisa čuvene slike Džordža Vašingtona koji prelazi Delaver tokom Američke revolucije: 1 . Vašington i njegove trupe prelaze Delaver; 2 . trupe pod vođstvom generala Džordža Vašingtona prelaze noću preko zamrznute reke Delaver.

Kineski ispitanici zamoljeni da opišu neku srdačnu i milosrdnu osobu verovatno će reći Fej grli svoje prijatelje na zabavama ili Džing daje novac prosjacima na ulici.Amerikanci će pre izjaviti Meri je brižna ili Bil je velikodušan. Prve dve rečenice pružaju više informacija nego dve potonje. Izraz srdačan ističe postojane crte neke osobe. Glagolska grupa grli svoje prijatelje na zabavama ukazuje na ograničenu prirodu osobina. Češća upotreba glagolskih grupa kod Kineza omogućava im da odrede okruženje u kojem jedinka ispoljava ponašanje ili emociju.

Kejgan se fokusirao na komparaciju sledećih rečenica:1. Gojazni adolescenti jedu previše ugljenih hidrata na žurkama. 2. Prekomerno unošenje ugljenih hidrata na žurkama dovešće do gojaznosti adolescenata. Prva rečenica ukazuje na nečiju postojanu sklonost. Druga ukazuje da se navike $u$ ishrani na žurkama možda razlikuju od uobičajenih, te da stoga mogu da se promene. Govornici koji imaju na umu odlike, akcije, uloge i društvene odnose svakog pojedinca u okruženju u kojem su se obreli, trebalo bi da koriste glagolske grupe. Sklonost ka upotrebi imenica i prideva u opisivanju jedinki, podseća na stereotipnu koncepciju, dok glagolske grupe ukazuju na blagonakloniji pogled na jedinke. Velikih pet obeležja karaktera, američki izum, jesu pridevi van konteksta ekstrovertnost, savesnost, neuroticizam, otvorenost, saradljivost. Nijedan azijski psiholog ne bi izmislio velikih pet.

O nameravanom i nenameravaonm značenju glagola i imenica istakao je da postoji manje kategorija raznovrsnijih glagola, nego imenica. Kao rezultat toga, glagoli obično zahtevaju određenje konteksta kako bi se odgnonetnulo njihovo nejasno značenje.

Nameravano značenje imenica voda, pas i dete, jasnija je od nameravanog značenja glagola pasti i juriti, zato što voda, pas i deca padaju i jure na različite načine. Stoga se uz mnoge glagole mora dodati imenica koja ukazuje na subjekat ili na cilj neodređenog značenja. To bi mogao da 
bude jedan od razloga što se korteks snažnije aktivira kad subjekt pročita samo glagole na ekranu, nego kad pročita imenice. Glagoli zahtevaju veće mentalno naprezanje. Engleski glagoli ubiti, optužiti i unajmiti, koji ukazuju na ljudski subjekat i objekat, kao i na nameru, predstavljaju izuzetke. Valja napomenuti da je to zapažanje nevažno za opažajnu šemu stanja mozga. Svako stanje mozga je nužno kontekstualizovano, a uzrok svake šeme je neki događaj u izvesnom kontekstu.

Razmena reči između ljudi zavisi od njihove želje da utiču na svoje odnose s drugima, kao i da očuvaju priteljsku vezu ili da zadive nekog, da ga kontrolišu, povrede ili zavedu. Američki psiholozi obično zanemaruju taj motiv kad od ispitanika traže da popune upitnike. Polaze od toga da su pažnje vredni samo sadržaj pitanja i istinitost odgovora i očekuju da većina ispitanika pruži iskrene, precizne odgovore na ta pitanja. To je naivna premisa. Odnos moći između psihologa i ispitanika obično je neravnopravan, te se ispitanik trudi da ne ostavi loš utisak.

Japanci su uznemireniji od amerikanaca kad treba da ostave poruku na telefonskoj sekretarici, jer in brine kako će pozvana osoba protumačiti verbalnu poruku.

Dvojica japanskih rukovodilaca ili naučnika koji se prvi put sreću odmah će razmeniti vizit karte, kako bi saznali društveni položaj svog sagovornika i odlučili kako da se, shodno tome, postave prema njemu. Amerikanci bi taj običaj smatrali neuljudnim.

Strogo gledano, pripadnike zapadnih društava pre svega zanimaju empirijski proverene ideje, koje istrajavaju bez obzira na okolnosti.

Pripadnicima azijskih kultura važna je istina, ali i tanani aspekti međuljudske komunikacije, koji utiču na sklonosti i svojstva odnosa sa drugima.

Kejgan kaže da isticanje salijentnog objekta u prvom planu čije se odlike zadržavaju bez obzira na okruženje, u poređenju s prisnim stapanjem objekta i pozadine, predstavlja ključnu razliku između Zapada i Istoka. Argument koji bi mogao da pomogne u razumevanju te kulturološke različitosti, oslanja se na klimatske, ekonomske i društvene razlike između te dve koncepcije.

Stara Kina bila je pre svega zemljoradničko društvo koje su činila sela i zaseoci, gde su česte i pogubne prirodne nepogode, suše i poplave, dovele do uzajamne zavisnosti iszmeđu ljudi i prirode.Narodnih umotvorina koje dočaravaju saradnju između ljudi i životinja ima više u kineskoj knji- 
ževnosti nego u evropskom narodnom stvaralaštvu. U evropskim bajkama tipa Crvenkapa, životinje su opasna pretnja koju treba izbeći.

Za razliku od kineskog, starogrčko društvo je bilo pretežno trgovačko, užival oje u pitomijem okruženju i slavilo je neobično hrabre i darovite pojedince. Postoji vrlo malo kineskih drama, spevova ili romana, koji se mogu uporediti sa Homerovom Odisejom, a čije su teme istrajna odvažnost i veština jednog čoveka.

U kineskoj književnosti počast se daje mudrim carevima i brižnim poglavarima, koji služe narodu i upravaljaju njime, odgovorni su za njega i odani su mu.

Spoznaja Grka o raznorodnosti pojava, jezika, običaja i institucija njihovih trgovinskih partnera u Sredozemlju i na obalama Egejskog mora, u poređenju sa homogenijim kineskim društvom, možda je navela Grke da ističu postojanje razlike među ljudima. Te suprotnosti između različitih kultura koje se ogledaju u ekonomskim i ekološkim obrascima, kao i u odnosu prema prirodi, odredile su tri hiljade godina kasnije, kako će se jezik koristiti da bi se njime opisali ljudi i njihove emocije.

\section{Diskretne emocije ili razlike u salijentnosti ${ }^{5}$}

Pitanje je da li različite reči za označavanje emocija za koje naučnici pretpostavljaju da pripadaju istoj porodici odražavaju varijaciju na kontinuumu salijentnosti ili predstavljaju kvalitativno odvojena stanja? To pitanje je svakako povezano s raspravom o tome da li svesni ili nesvesni procesi počivaju u kontinuumu ili su zasebni fenomeni. Da li se izraz autistički spektar odnosi na jednu bolest sa simptomima različitog inteziteta ili su različiti simptomi odraz bolesti s posebnim uzrocima. Semantički skup reči srećan, radostan i ushićen koje tri osobe izaberu po jednu reč za opis venčanja. Ukoliko i moždani i bihevioralni dokaz otkrivaju različite profile u navedenom semantičkom skupu, možemo se zapitati da li tri osobe doživljavaju tri različita emocionalna stanja ili varijacije istog tipa. Isti problem važi i za izraze tužan, žalostan i potišten.

Kejgan je postavio isto pitanje kada se radi o razlikovanju porekla neke emocije. Da li strah ili opčinjenost predstavlja varijaciju stanja koje se

$5 \quad$ Kejgan Dž, Šta je emocija, 2015 
javlja dok neko vozi kroz zaslepljujuću mećavu ili su to kvalitativno posebne emocije? Osim toga, različiti uzroci mogu da izazovu posebne emocionalne mešavine, što je ilustrovao primerima tipa: 1) Stanje vijetnamskih veterana s posttraumatskim stresom mešavina je anksioznosti i krivice zbog učestvovanja u okrutnim akcijama nad nedužnim civilima ili prisustvovanja tim akcijama. 2) Stanje starije osobe koja je nehotice zalupila vrata ostavivši ključ u kući kombinacija je ljutnje i anksioznosti zbog mogućeg gubitka mentalnih sposobnosti. 3) Emocija usmerena ka susedu koji je zapustio svoj travnjak mešavina je ljutnje i anksioznosti, zato što susedova ravnodušnost predstavlja pretnju po moralne standarde svakodnevnog života. Tuga koja prati gubitak majke često je pomešana sa osećajem krivice zbog nedovoljne privrženosti majci dok je bila živa. 4) Nasuprot tome, tuga koju neko oseti kad izgubi posao često je pomešana sa anksioznošću za imovno stanje u budućnosti. Jačina i poreklo osećanja mogu da utiču na procenu njegove valence i ponašanje. Blago ubrzanje srčanog ritma i mišićne napetosti koju neko oseti pre nego što se ukrca na tobogan smrti obično se tumače kao uzbuđenje, dok će se veliko povećanje amplitude te dve reakcije pre protumačiti kao strah.5) Kad psiholozi dublje proniknu u veze između nadražaja i moždanih obrazaca, osećanja i tumačenja koja slede, lakše će moći da zaključe da li semantičke opise srećan, radostan i ushićen treba posmatrati kao različite intezitete istog stanja ili kao kvalitativno različite emocije. 6) Voda i led kvanitativno se razlikuju na kontinuumu temperature, ali imaju kvalitativno različite strukture i oblike.

Naučnici koji su proučavali psihološka stanja ljudi, priznali su potrebu da razdvoje izraze koje jedinke koriste da opišu svoje emocije od teorijskih izraza kojima bi trebalo objasniti povezane varijacije događaja, $s$ jedne, i beihevioralnog ili biološkog ishoda, s druge strane. Ta razlika ima zajedničke odlike $s$ antropološkom suprotnošću između emičkih i etičkih opisa. Čovekova subjektivna procena sopstvenog društvenog položaja u izvesnoj meri bolje ukazuje na njegovo zdravlje, nego sociološki objektivni indeksi društvenih klasa. Obučeni ocenjivači koji procenjuju emocionalna svojstva i intezitet ispitanikovih snova, pripisaće manju salijentnost i manje prijatnu valencu snovima od onoga koji ih je usnio.

Jedan od razloga za skromnu, često zapostavljenu vezu između samoopisivanja osećanja i emocija, s jedne strane, i bioloških ili bihevioralnih merenja, s druge, leži u činjenici da se uobičajeni nivoi nesigurnosti u stimulus i reaktivne neodlučnosti ljudi razlikuju. Među onima koji su 
uglavnom opušteni, osećaj neodlučnosti je neočekivan i stoga izražen i lakše upamtljiv. Među onima koji se obično ponašaju neodlučno, trenuci spokojne opuštnosti predstavljaju nedoslednost i zato se lakše pamte. Shodno tome, kada psiholozi zamole ta dva tipa ljudi da opišu svoje uobičajeno osećanje pred ispite, veliki deo prve grupe reći će da su zabrinuti, dok će više pripadnika druge grupe reći da su opušteni.

Drugi problem s verbalnim izveštajima o emocijama jeste uslov da se pitanja prilagode jezičkom repertoaru ispitanika. Na primer, psiholozi ne mogu da pitaju roditelje da li imaju ambivalentan stav prema svojoj deci ili učenike dali osećaju acediju (duhovnu prazninu). lako većina ljudi može da prepozna izraz lica čoveka dok prezrivo gleda one koje smatra manje vrednima, teško da će bilo ko takav izraz lica nazvati kontemptibilnim jer se taj izraz retko upotrebljava.

Treće, ljudi gaje predubeđenja u pogledu svojstava i inteziteta emocija za koje smatraju da zaslužuju da ih iskuse s obzirom na svoj pol, uzrast ili etničku pripadnost. To je jedan od razloga što američke žene obično izveštavaju o intenzivnijim emocijama nego muškarci, iako je reč o istom nadražaju, i što afroamerički studenti koji kažu da se snažno poistovećuju sa svojom etničkom grupom poriču da brinu o bilo čemu. (Kejgan 2015: 220)

Stoga je potvrdio da je valjanost zaključaka o emocijama ili njihovim varijacijama, zasnovanih isključivo na upitnicima ili razgovorima, nužno ograničena na taj izvor dokaza. Nijedan istraživač primata ne bi postavio teoriju psihologije šimpanza zasnovanu samo na snimcima njihovog glasovnog izražavanja, zanemarujući pritom bihevioralne ili biološke informacije i opise konteksta u kojem je došlo do glasovnog izražavanja. Srednjevekovni tumači Biblije su posvetili stotine sati hermeneutičkoj analizi svetih tekstova uvereni da će, ako insistiraju, moći da dokuče istinsko značenje svake rečenice. Oni koji su čitali Guliverova putovanja Džonatana Svifta prisetiće se kako je autor satirično dočarao one koji su tvrdili da jezik ima moć da precizno opiše prirodu. Svift je opisao dvojicu filozofa koji su na debatu doneli velike vreće pune predmeta, da bi pomoću njih svoje argumente učinili razumljivim. Ta nespretna strategija mogla bi da pomogne u razjašnjavanju značenja cigala, brokolija i balona, ali nije primenjiva na emocije.

Navedeni dokazi ukazuju na potencijalnu svrsishodnost kombinovanja porekla (spoljnih događaja, misli ili spontane moždane aktivnosti), stanja mozga, subjektivne procene valence i salijentnosti osećanja (na koje utiču očekivanost i poznatost) i semantičkog određenja prilikom katego- 
rizacije emocija. Promena u bilo kojoj od navedenih odlika mogla bi da predstavlja posebnu emociju. ${ }^{6}$

\section{Umesto zaključka}

$\mathrm{Na}$ osnovu psiholinvističkog istraživanja i ekscerpirane građe, da se zaključiti da semantička asocijativna polja, postojanost i promenljivost emocija, dvosmislenost reči koje su utemeljene na različitim kulturološkim sistemima, kroz prizmu jezičke paradigme, daju preciznu komunikativnu sliku čoveka kao individue u određenoj društveno jezičkoj zajednici. Kognitivna lingvistika predočava da se značenje temelji na kolektivnom ljudskom iskustvu, koje je vezano za telesnu egzistenciju.

Kultura, kulturni identitet, tradicija i pamćenje našle su svoj odraz u jeziku. Jezički ekvivalenti se različito tumače i predstavljaju u različiim jezičko kulturnim zajednicama, iako su navedene četiri emocije univerzalne kategorije.

Analiza asocijativnih polja pokazuje da postoje značajne razlike u ličnim i kolektivnim iskustvima materijalne realnosti kod različitih naroda. Takođe postoje i podudaranja u emocionalnim i psihičkim funkcijama različitih etnosa, ali i semantičko, odnosno leksičko preklapanje.

Lekseme su povezane pojmovima valence i salijentnosti emocija,

$6 \quad$ Kejganov primer je neočekivan kritički stav roditelja u porodičnom kontekstu, koji pobuđuje poseban profil mozga, salijentnost, neprijatno opažanje ubrzanja srčanog ritma, grčenje čeonih mišića i tumačenje da je kritički stav roditelja motivisan njihovom željom da pomognu adolescentu da razvije bolje karakterne navike, doveo bi do stanja drugačijeg od onog koje bi se javilo ako bi četiri navedene odlike bile iste, ali bi adolescent protumačio primedbu roditelja kao nepravednu i motivisanu njihovom netrpeljivošću prema njemu. Treća emocija ostvarila bi se ukoliko bi njen uzrok bilo uzgredno prisećanje na pomenuti slučaj. Četvrto stanje bi se ispoljilo ukoliko bi kritika bila očekivana. Biološki važan ishod kao što je odnos broja muških i ženskih jedinki kod kičmenjaka koji se legu iz jaja, može da zavisi od neznatne promene temperature u sredini u kojoj se oplođena jaja razvijaju. Nespremnost da se priznaju izuzetne specifičnosti emocionalnih fenomena usporava napredak teorije o emociji. Naučnici kojima ova primedba nije po volji trebaju da prouče tekst u kojem se opisuje izuzetna biohemijska složenost ćelije karcinoma.

Dobar primer je opažanje boja. lako 1269 boja Munselovog sistema nastaje kombinovanjem 3 dimenzije vrednosti boje: osvetljenosti, tonaliteta i zasićenosti, ljudi mogu da razlikuju svih 1969 površina. Ponekad je korisno posmatrati sve crvene tonalitete kao slične. U drugim prilikama za teoriju će biti korisnije ako se napravi razlika između purpurne i ružičaste ili između kratkotalasnih ljubičastih i plavih, i dugotalasnih tonaliteta crvene i narandžaste. Isto načelo važi za emocije. 
koje su vrlo izazovne za istraživanje. Značenje se pojačava ili smanjuje zavisno od uloge emocije u navedenim primerima u određenoj jezičkoj zajednici. Emocije kao psiholingvističa kategorija, manifestuju se kulturološki individualno u kolektivnoj zajednici.

Mada nijedna teorija ne pokriva sve činjenice (Šušnjić: 2015:195) metodi koje se izvode iz nje su samostalnog položaja, što je potvrđeno u ovoj analizi. Uočeno je da nema čvrste semantičke veze između emocija i reakcija, jer je kolektivni identitet određen društveno i teritorijalno. Posebni identiteti nisu isključili jedan drugog, a kolektivni u rasponu od lokalnog do nacionalnog su definisali statuse ljudi, mada su stalnim migracijama ljudi postali kako multukulturalni tako i multilingvalni. Globalizacija i internacionalizacija su pomerile granice jezika, kultura i generičkog značenja emocija.

Preliminarno je dokazano da lekseme za označavanje emocija imaju različite semantičke dimenzije od kulture do kulture, a da se u nekima i preklapaju. Asocijacije i metafore sužavaju ili proširuju značenje emocija jer su kulturološkog karaktera. Neke od njih su potpuno ekvivalentne u kulturama i jezicima, a neke potpuno specifične za jedan jezik, što je ilustrovano mnogobrojnim primerima.

Semantičko značenje emocija je određeno njihovim emitovanjem u kulturi ciljnog jezika, što je predmet funkcionalističkih translatoloških teorija.

Lingvokognitivni aspekt jezika je usmeren na jezik i misao, čiji je ključ analize upravo razumevanje mišljenja kroz jezik. Jezički ambiguitet i dvosmislenost pokazali su se zavisnim isključivo od učesnikovog poimanja sveta.

Leksička organizacija emocija obuvatila je interdisciplinarnu analizu, jer uključuje poznavanje nekoliko nauka, u cilju njihovog eksplicitnog prepoznavanja i izražavanja.

Poentirane su imenice i pridevi koji označavaju emocije prevashodno u engleskom jeziku, a onda i u drugim jezicima iz četiri domena sreće, tuge, straha i besa. Metaforične lekseme napravile su realnost koja je produkt ničeg drugog do ljudskog iskustva, percepcije i shvatanja sveta.

Sa lingvokognitivnog aspekta za opis emocije nužno je potrebno sagledati i istražiti značenje emocije i percepciju situacije, odnosno konteksta, jer je u lingvistici poznato da se emocije najčešće izražavaju metonimijom i metaforom. Pokazalo se da je komunikacija kroz različite kulture potpuno različita, jer je temelj svake kulture u genetskom kodu i nasleđu. Naučnici su dokazali da ljudi poseduju samo četiri emocije, koje se ispoljavaju u različitim nijansama i tonalitetima kroz različite društveno jezičke zajednice, odnosno jezičke sisteme. 


\title{
Reference
}

Bojović B. (2016) Osnovi translatogije, Filološki fakultet Nikšić, (Poglavlje o kulturi i prevodu)

Kejgan Dž. (2015) Šta je emocija?,Beograd, Zavod za udžbenike

Уфимцева, Н.В. (2011). Языковое сознание: динамика и вариативность. Москва: Российская академия наук. Институт языкознания.

Šušnjić Đ. (2015) Teorije kulture, Beograd, Zavod za udžbenike

\author{
Brankica Bojović \\ Alfa University of Belgrade
}

\section{THE SEMANTIC POTENTIAL OF EMOTIONS THROUGH LANGUAGES AND CULTURES}

\section{Summary}

This paper analyses emotions and their semantic and linguo-cognitive potential, which in a collocative sense through different languages and cultures convey an entirely different emotional experience. The theoretical postulate of this paper is the development of the psycholinguistic theory of knowledge, that is, the psycholinguistic aspect of language labels for emotions and expressions that convey meaning about emotional experience. In academia, the view that humans have six emotions is outdated, and recent studies have shown that there are only four: happiness, sadness, fear and anger. This paper focuses on semantic analysis of those emotions and their linguistic realisation in human communication. Cultural elements are an integral part of psychological factors, measured in the dimensions of valence, or value-scales, from pleasant to unpleasant and salience, or displayed irritation, from low to high. Emotion and culture have been semantically united who knows how many times, starting from man's physical to emotional experience of a wide range of different identities and cultures.

Key words: psycholinguistics, emotion, culture, valence, salience, linguistic realisation 